\title{
Looking back at 2019 in Regenerative Medicine
}

\author{
Adam Price-Evans*,1 \\ ${ }^{1}$ Managing Editor, Future Science Group, Unitec House, 2 Albert Place, London N3 1QB, UK \\ *Author for correspondence: a.price-evans@futuremedicine.com
}

First draft submitted: 4 March 2020; Accepted for publication: 4 March 2020; Published online: 11 March 2020

Keywords: induced pluripotent stem cell • mesenchymal stem cell • osteoarthritis • regenerative medicine • RegMedNet $\bullet$ stem cell $\bullet$ translation

\section{Our content in 2019}

I would like to welcome all of our readers to Volume 15 of Regenerative Medicine. We had an exciting year in 2019, with a rise in frequency to 12 issues per year, allowing us to publish even more of the latest high-quality research in clinical translation, commercialization and regulation in this rapidly evolving field.

As a specialist forum addressing the important advances and challenges in the field of regenerative medicine, in Volume 14, we published a large selection of highly impactful and insightful articles across a wide range of topics. Table 1 details the ten most-read articles from 2019 in Regenerative Medicine [1-10].

At the time of writing, the most read Regenerative Medicine article published in 2019, and already one of the journal's most highly read articles ever, is a Research Article entitled, 'Adipose-derived mesenchymal stem cell therapy in the treatment of knee osteoarthritis: a randomized controlled trial' [1]. The authors describe the first randomized controlled clinical trial evaluating the safety and efficacy of autologous isolated and expanded adipose-derived mesenchymal stem cell (ADMSC) therapy in the treatment of symptomatic knee osteoarthritis. Interestingly, the study tested different dosing regimes and involved three treatment groups: control, one injection of $100 \times 10^{6}$ ADMSCs (at baseline) and two injections of $100 \times 10^{6}$ ADMSCs (at baseline and 6 months). Over a 12month follow-up, the study recorded statistically and clinically significant improvements in pain and function in both ADMSC treatment groups compared to control and baseline. Using magnetic resonance imaging-based Osteoarthritis Knee Score assessment, they also demonstrated modification of disease progression over 12 months of follow-up, with greatest stabilization achieved by the treatment group receiving two injections of ADMSCs.

Given the great interest in this area of research, we were delighted to also recently publish the findings of a Phase IIa proof-of-concept randomized single-blind clinical trial studying the safety and efficacy of intra-articular injections of human adipose-derived mesenchymal progenitor cells, in combination with hyaluronic acid and microfracture, for the treatment of cartilage defects [11].

The second most read article published in 2019 was the Review article 'Toward a unified theory of aging and regeneration' [2]. In this article, authors discuss a unified mechanistic model for the etiology of aging and loss of regenerative potential, which could potentially be translated to novel therapeutic approaches involving the restoration of regenerative capacity in aging tissue and organs.

The Commentary entitled 'Preparing regenerative therapies for clinical application: proposals for responsible translation' [3] was the third most read Regenerative Medicine article of Volume 14, and the most read shorter article type. This work provides an overview of the multidisciplinary Regenerative Therapeutics Program implemented in recent years at the Mayo Clinic Center for Regenerative Medicine (MN, USA), which is designed to translate valid regenerative therapies for multispecialty practice by reducing common obstacles through patient education, implementation of quality control and procedural integrity and the collection of real-world evidence to validate its use.

Despite it not being published in 2019, I'd also like to highlight the White Paper 'Quality control guidelines for clinical-grade human induced pluripotent stem cell lines', which was the second most read Regenerative Medicine 


\begin{tabular}{|c|c|c|c|c|}
\hline Rank & $\begin{array}{l}\text { First author } \\
\text { name }\end{array}$ & Title & Article type & Ref. \\
\hline 1 & Julien Freitag & $\begin{array}{l}\text { Adipose-derived mesenchymal stem cell therapy in the treatment of knee osteoarthritis: a randomized } \\
\text { controlled trial }\end{array}$ & Research article & [1] \\
\hline 2 & Michael D West & Toward a unified theory of aging and regeneration & Review & [2] \\
\hline 3 & Shane A Shapiro & Preparing regenerative therapies for clinical application: proposals for responsible translation & Commentary & [3] \\
\hline 4 & Mukta S Sane & Characterization of an umbilical cord blood sourced product suitable for allogeneic applications & Research article & [4] \\
\hline 5 & Pedro S Couto & $\begin{array}{l}\text { First decade of clinical trials and published studies with mesenchymal stromal cells from umbilical cord } \\
\text { tissue }\end{array}$ & Research article & [5] \\
\hline 6 & Alison Wilson & $\begin{array}{l}\text { Nomenclature and heterogeneity: consequences for the use of mesenchymal stem cells in regenerative } \\
\text { medicine }\end{array}$ & Perspective & [6] \\
\hline 7 & Paul S Knoepfler & Rapid change of a cohort of 570 unproven stem cell clinics in the USA over 3 years & $\begin{array}{l}\text { Short } \\
\text { communication }\end{array}$ & [7] \\
\hline 8 & Joan Oliva & Engineering, differentiation and harvesting of human adipose-derived stem cell multilayer cell sheets & $\begin{array}{l}\text { Preliminary } \\
\text { communication }\end{array}$ & [8] \\
\hline 9 & Dusko llic & Industry updates from the field of stem cell research and regenerative medicine in February 2019 & Industry news & [9] \\
\hline 10 & Glyn Stacey & $\begin{array}{l}\text { Stem cell culture conditions and stability: a joint workshop of the PluriMes Consortium and Pluripotent } \\
\text { Stem Cell Platform }\end{array}$ & White paper & [10] \\
\hline
\end{tabular}

article last year. This article outlines an international consensus of critical quality attributes and minimum testing requirements for clinical-grade induced pluripotent stem cell lines [12].

Other articles published in previous volumes that were highly popular in 2019 include:

- 'A brief definition of regenerative medicine' [13]

- 'Fibroblasts and wound healing: an update' [14]

- 'Mesenchymal stem cell exosome: a novel stem cell-based therapy for cardiovascular disease' [15]

- 'Direct-to-consumer marketing of stem cell interventions by Canadian businesses' [16].

Our top-scoring paper on the Altmetric platform [17] in 2019 was the aforementioned Commentary by Shapiro et al. discussing the Mayo Clinic Regenerative Therapeutics Program [3]. This work received attention from numerous news outlets from around the world, which contributed to its high Altmetric score. Another highly successful article on the Altmetric platform in 2019 was the Commentary entitled, 'Engineering strategies for generating hypoimmunogenic cells with high clinical and commercial value' [18]. This piece discusses the remaining obstacles and knowledge deficits to commercial generation of 'universal', hypoimmunogenic stem cells for use in regenerative medicine and advanced therapies.

\section{Regenerative Medicine around the world}

As the regenerative medicine research community continues to grow, the readership of Regenerative Medicine changes. In 2019 , our content was most read by experts in the USA $(\sim 36 \%)$, China $(\sim 9 \%)$ and the United Kingdom $(\sim 8 \%)$. The proportion of readership in the USA actually went up by $6 \%$ last year compared to 2018 [19]. Figure 1 depicts the approximate proportions of the Regenerative Medicine readership by continent. While our content continues to have impact across North America, Asia and Europe, we expect to see a continued growth in emerging scientific communities and look forward to continuing the circulation of our content to an increasingly global audience.

Similarly, we continue to attract submissions from authors all over the world. Figure 2 highlights where our authors are carrying out their research.

\section{Social media}

Regenerative Medicine's social media presence has continued to grow throughout 2019. We were delighted to reach over 3100 followers on the journal's Twitter account (@Regen_Med) [20] and this number continues to rise. The journal also has a LinkedIn group, open to all [21]. We regularly post journal highlights across these platforms, including newly published content and issues, offers and the latest news in the field. 


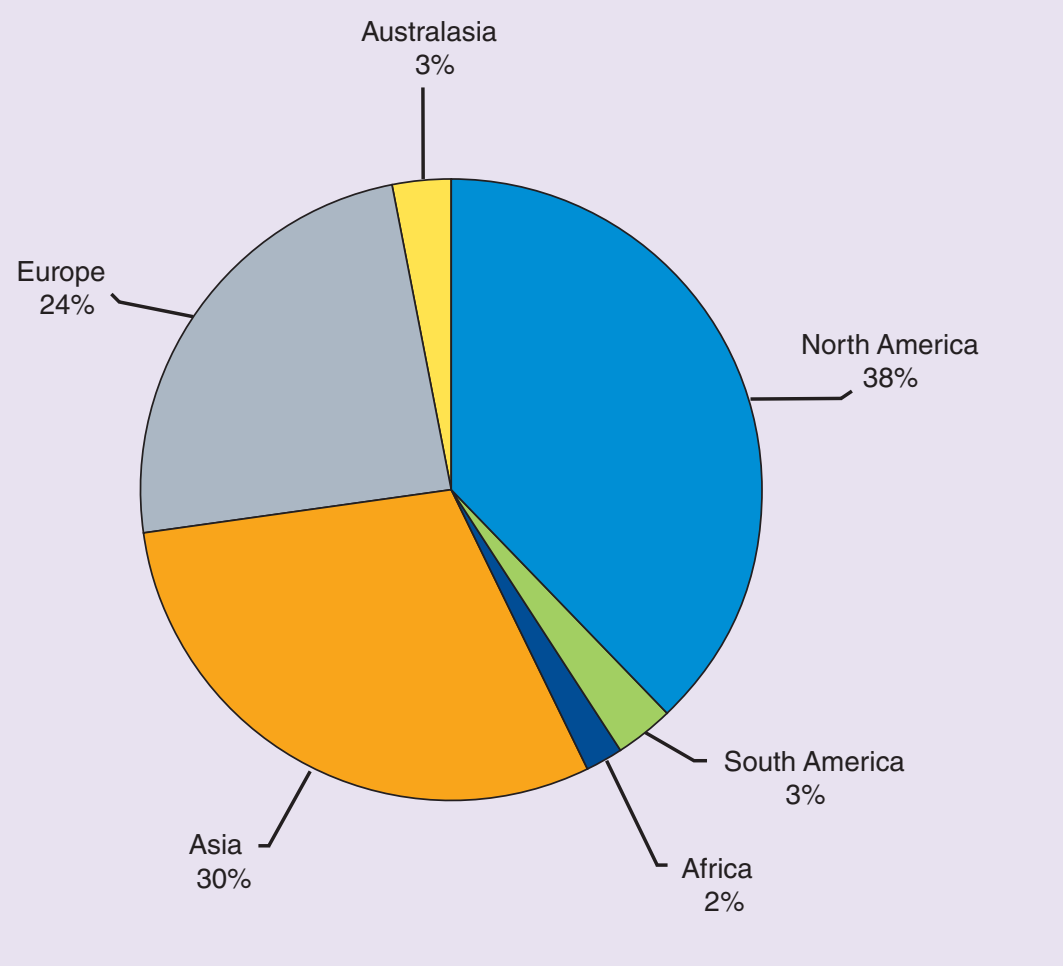

Figure 1. Approximate Regenerative Medicine readership demographics in 2019 (by continent).

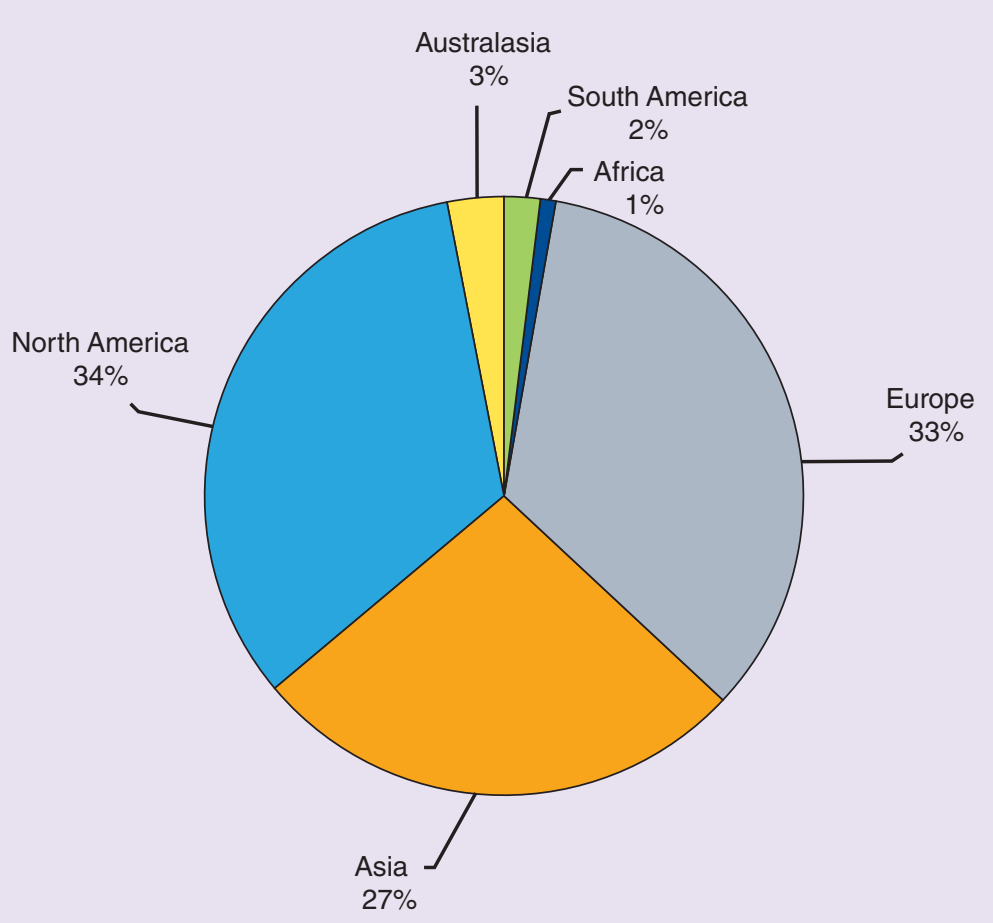

Figure 2. Approximate Regenerative Medicine authorship demographics in 2019 (by continent). 


\section{RegMedNet}

Regenerative Medicine is proud to be partnered with and work alongside RegMedNet [22], a free-to-access community website with over 15,000 members. RegMedNet aims to promote global collaboration within the diverse regenerative medicine field and provides up-to-date and essential information on all aspects of regenerative medicine, from the bench to the bedside. RegMedNet offers easy access to breaking news, exclusive features, interviews, video content, webinars and peer-reviewed journal articles from Regenerative Medicine.

The journal's partnership with RegMedNet provides us the unique opportunity to further showcase and disseminate work published in Regenerative Medicine across multiple platforms and to a wider audience, adding great additional benefit to our authors and further driving the influence and reach of their work.

With this in mind, RegMedNet continues to publish the 'Peek behind the paper' feature, which gives Regenerative Medicine authors the chance to offer additional perspectives on their article and provide our audience with further insight into their research. For example, in 2019, RegMedNet published accompanying video and written interviews from two co-authors, allowing them to discuss their article [3] across different formats and offer both clinical and ethical perspectives on responsible translation and the Mayo Clinic Regenerative Therapeutics Program [23].

In keeping with our desire to deliver essential information in concise, clear and attractive formats, in 2019, we also updated how we deliver our regular Industry Updates column from Regenerative Medicine Editorial Board member, Dusko Ilic (King's College London, UK). Alongside offering access to the full Industry News articles published in each issue of the journal, Ilic now offers his thoughts and opinions on some of the latest industry advances, exclusively for the RegMedNet audience. Since moving to this new format, readership of the updates has increased by over $200 \%$ on RegMedNet.

Another new and successful format, tried and tested on RegMedNet in partnership with Regenerative Medicine this year, were hour-long, filmed, discussion-based panels [24], which bring interdisciplinary and international expertise together to explore the challenges and opportunities around the commercialization of regenerative medicine. This year alone, experts from renowned institutions such as Lonza Pharma $\&$ Biotech (Basel, Switzerland), REGENXBIO (MD, USA), Maxcyte (MD, USA), Wake Forest Institute for Regenerative Medicine (NC, USA), University of Pennsylvania (PA, USA) and the National Institute of Standards and Technology (NIST; MD, USA) have discussed patient safety, real-world evidence, supply chain investment, quality and safety assurance and more.

\section{Conference attendance}

In late 2019, Regenerative Medicine had the honour of supporting 3DMedLIVE [25], a dynamic, conversation-led and solution-focused event which shared case studies directly from pioneering surgeons and researchers who are already utilising $3 \mathrm{D}$ printing technology in their practice, plus panel discussions and roundtables with regulators, manufacturers and funders. The event was a huge success, welcoming over 150 delegates to London for two days of collaboration and knowledge-sharing and we very much look forward to the next meeting in 2020.

As we do every year, in 2019, members of the Regenerative Medicine team also attended a number of other international conferences, meetings and events in order to meet our readers, authors, Editorial Board members and collaborators, as well as keep up-to-date with the field and ensure that we are covering all the latest and ground-breaking research. Some of the key events we attended include the World Stem Cell Summit in Miami (FL, USA), the annual International Society for Stem Cell Research (ISSCR) meeting in Los Angeles (CA, USA), the American Society of Gene and Cell Therapy (ASGCT) Annual Meeting (DC, USA) and the Advanced Therapies Congress (London, UK).

In order to keep up to date with the events that our team will be attending in 2020, follow us on Twitter [20], join our LinkedIn group [21] or become a member of RegMedNet [22].

\section{Conclusion}

We appreciate all feedback from the regenerative medicine community regarding the direction of our content, especially suggestions of any priority topics in the field that you feel the journal should cover. We welcome unsolicited research, review and opinion article proposals, amongst others, and would be delighted to hear from you if you are interested in submitting to the journal.

I would also like to take this opportunity to thank our readers, contributing authors, valued Editorial Board members and peer reviewers for their continued support and collaboration as we continue to publish the latest advances in the field. We very much look forward to working with you all over the next year and hope to see Regenerative Medicine continue to grow and serve the research community in 2020. 


\section{Financial \& competing interests disclosure}

Adam Price-Evans is an employee of Future Medicine Ltd, publisher of Regenerative Medicine. The author has no other relevant affiliations or financial involvement with any organization or entity with a financial interest in or financial conflict with the subject matter or materials discussed in the manuscript apart from those disclosed.

No writing assistance was utilized in the production of this manuscript.

\section{References}

1 Freitag J, Bates D, Wickham J et al. Adipose-derived mesenchymal stem cell therapy in the treatment of knee osteoarthritis: a randomized controlled trial. Regen. Med. 14(3), 213-230 (2019).

2 West MD, Sternberg H, Labat I et al. Toward a unified theory of aging and regeneration. Regen. Med. 14(9), 867-886 (2019).

3 Shapiro SA, Smith CG, Arthurs JR, Master Z. Preparing regenerative therapies for clinical application: proposals for responsible translation. Regen. Med. 14(2), 77-84 (2019).

4 Sane MS, Tang H, Misra N et al. Characterization of an umbilical cord blood sourced product suitable for allogeneic applications. Regen. Med. 14(8), 769-789 (2019).

5 Couto PS, Shatirishvili G, Bersenev A, Verter F. First decade of clinical trials and published studies with mesenchymal stromal cells from umbilical cord tissue. Regen. Med. 14(4), 309-319 (2019).

6 Wilson A, Webster A, Genever P. Nomenclature and heterogeneity: consequences for the use of mesenchymal stem cells in regenerative medicine. Regen. Med. 14(6), 595-611 (2019).

7 Knoepfler PS. Rapid change of a cohort of 570 unproven stem cell clinics in the USA over 3 years. Regen. Med. 14(8), 735-740 (2019).

8 Oliva J, Florentino A, Bardag-Gorce F, Niihara Y. Engineering, differentiation and harvesting of human adipose-derived stem cell multilayer cell sheets. Regen. Med. 14(3), 151-163 (2019).

9 Ilic D. Industry updates from the field of stem cell research and regenerative medicine in February 2019. Regen. Med. 14(06), 495-504 (2019).

10 Stacey GN, Andrews PW, Barbaric I et al. Stem cell culture conditions and stability: a joint workshop of the PluriMes Consortium and Pluripotent Stem Cell Platform. Regen. Med. 14(3), 243-255 (2019).

11 Qiao Z, Tang J, Yue B et al. Human adipose-derived mesenchymal progenitor cells plus microfracture and hyaluronic acid for cartilage repair: a Phase IIa trial. Regen Med. doi: 10.2217/rme-2019-0068 (2020) (Epub ahead of print).

12 Sullivan S, Stacey GN, Akazawa C et al. Quality control guidelines for clinical-grade human induced pluripotent stem cell lines. Regen. Med. 13(7), 859-866 (2018).

13 Mason C, Dunnill P. A brief definition of regenerative medicine. Regen. Med. 3(1), 1-5 (2008).

14 des Jardins-Park HE, Foster DS, Longaker MT. Fibroblasts and wound healing: an update. Regen. Med. 13(5), 491-495 (2018).

15 Lai RC, Chen TS, Lim SK. Mesenchymal stem cell exosome: a novel stem cell-based therapy for cardiovascular disease. Regen. Med. 6(4), 481-92 (2011).

16 Turner L. Direct-to-consumer marketing of stem cell interventions by Canadian businesses. Regen. Med. 13(6), 643-658 (2018).

17 Altmetric (2020). www.altmetric.com

18 Malik NN, Jenkins AM, Mellon J, Bailey G. Engineering strategies for generating hypoimmunogenic cells with high clinical and commercial value. Regen. Med. 14(11), 983-989 (2019).

19 Price-Evans A. Introducing Volume 14 of Regenerative Medicine. Regen. Med. 14(1), 1-5 (2018).

20 Twitter (2020). https://twitter.com/Regen_Med

21 LinkedIn (2020). www.linkedin.com/groups/4383090

22 RegMedNet (2020). www.regmednet.com

23 RegMedNet. Peek behind the paper: Preparing regenerative therapies for clinical application: proposals for responsible translation (2019). www.regmednet.com/channels/713-regenerative-medicine-the-journal/posts/45820-peek-behind-the-paper-preparing-regener ative-therapies-for-clinical-application-proposals-for-responsible-translation

24 RegMedNet. Business of regenerative medicine expert panels (2020). www.regmednet.com/channels/1690-business-of-regenerative-medicine

25 3DMedLIVE (2020). http://3dmedlive.com/ 
